\title{
DE PROTAGONISTA A COADJUVANTE: O ÔNUS DAS VIRTUDES DE NARIZINHO
}

\author{
Adriana Lech Cantuária*
}

\begin{abstract}
RESUMO: A partir da análise de algumas das obras infantis de Monteiro Lobato, este artigo propõe uma reflexão sobre a mudança de status da personagem Narizinho na dinâmica de funcionamento do universo lobatiano. São focalizados aqui aspectos de sua trajetória de heroína dos textos reunidos em Reinações de Narizinho e sua transformação em coadjuvante nas aventuras e cenários posteriores, a partir da hipótese de que as concepções de infância, de gênero, bem como as demandas sociais e seus efeitos no mercado editorial da época teriam influenciado o autor na construção e desenvolvimento da personagem. A personagem Narizinho é a mais próxima dos adultos do Sítio e também a que mais legitima suas normas e valores, ao evocá-los constantemente e transgredi-los com moderação. A intensidade de sua participação em várias histórias e sua ausência em algumas ocorrem em oposição principalmente à atuação de Emília, personagem que se singulariza e agiganta-se ao longo da obra. Nesse contexto, Narizinho e suas virtudes parecem resquícios de uma tradição utilitarista de literatura para crianças, de caráter basicamente pedagógico, tendência esta que, no Brasil, Monteiro Lobato foi o primeiro a superar.
\end{abstract}

Palavras-chave: Literatura infantil. Personagens. Infância. Educação.

\section{From MAIN CHARACTER TO SECONDARY CHARACTER: THE BURDEN OF NARIZINHO'S VIRTUES}

ABSTRACT: Following the analysis of several of Monteiro Lobato's children's works, this article proposes a rethinking on the status of the character named Narizinho as it pertains to the development

Doutora em Educação e orientadora pedagógica da Rede Municipal de Educação de Campinas.E-mail: adrianalech@terra.com.br 
and dynamics of the "Lobato Universe". The hypothesis emphasizes that Narizinho's journey as a main character and heroine in the compilation of stories "Reinações de Narizinho" and her metamorphoses into a secondary character in the later plots and adventures are a direct result of the changes in Childhood conceptions, style, as well as in social demands and their effect on the literary market at the time. All the above factors have had a direct influence on the author's creation and development of Narizinho. Narizinho is the one character who is the closest to the adult world and she is also the one who validates its norms and values as she constantly recites them and seldom infringes on them. The frequency with which Narizinho appears in several stories and her absence in some are in direct contrast with the rise of the character named Emilia, who later becomes a larger than life character. In this context, Narizinho and her virtues seem to be remnants of a literature for children which make use of pedagogical utilitarian characteristics as a base, a trend in Brazil that was first surpassed by Monteiro Lobato himself.

Key words: Children's literature. Characters. Childhood. Education.

\section{Introdução}

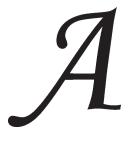

credito não ser exagero afirmar que, para várias gerações de brasileiros, o tema "personagens infantis" leva a evocar, quase automaticamente, a turma do Sitio do Picapau Amarelo.

Tal afirmação deve-se menos à constatação da evolução tecnológica das sociedades contemporâneas e do consequente avanço midiático que permitiu que a obra de Monteiro Lobato fosse veiculada pela televisão a milhões de crianças, mas ao fato, historicamente precedente, de que durante várias décadas a literatura infantil constituiu, por excelência, "a" produção cultural para crianças, ${ }^{1}$ período em que seus livros reinaram praticamente absolutos, resistindo incólumes à passagem do tempo.

A rigor, datam do final do século XIX os primeiros textos infantis produzidos no Brasil e, nas duas primeiras décadas do século $\mathrm{XX}$, autores como Júlia Lopes de Almeida, Olavo Bilac, Coelho Neto, entre outros, assinavam obras consagradas. Com conteúdo patriótico e retórica ufanista, tais obras, entretanto, possuíam um caráter didático e moralizante, constituindo a "literatura escolar" de que nos fala Lajolo (1982). 
Lobato, por outro lado, mesmo detentor de um projeto nacional definido - que ele deixa claro em vários de seus livros - e de um forte propósito educativo, rompeu com a tradição utilitarista e inaugurou uma nova estética na literatura para crianças; inovação esta relativa tanto ao plano da retórica quanto da ideologia. Com um discurso coloquial, entremeado de expressóes populares e neologismos, o escritor capta os leitores em sua rede ficcional, desperta seu interesse, estimula sua curiosidade, sua liberdade de pensar e agir, sua criticidade, e diverte-os (Perrotti, 1986; Zilberman \& Magalhães, 1984).

Não é por acaso, portanto, que Monteiro Lobato é considerado o fundador da literatura infantil brasileira. $\mathrm{O}$ fato de que a qualidade e longevidade de sua obra permitiram que seus cenários e personagens fossem constitutivos do imaginário de um sem número de sujeitos, por sua vez, torna impossível resistir ao impulso de tomar como objeto de análise uma destas personagens.

Foi assim que acabei me arriscando nesta temerária empreitada. A escolha, no caso, recaiu sobre Narizinho, por duas razóes. A primeira delas é que Reinaçóes de Narizinho, para muitos, representou o ritual de passagem para o mundo da leitura, sendo essa personagem a orientadora do percurso iniciático rumo ao Sitio do Picapau Amarelo. A segunda razão é a evidente mudança de rumo no projeto original de Monteiro Lobato - em que a saga do Sítio tinha como eixo a trajetória de Lúcia, a Narizinho - objetivada na ascensão da boneca Emília à posição de liderança entre as demais personagens.

$\mathrm{O}$ que se percebe a partir da leitura das obras completas, entretanto, não é apenas o crescimento da participação e da importância da boneca no corpo das histórias, mas também um "apagamento" paulatino das cores da heroína Narizinho.

A destemida, curiosa e arteira protagonista de Reinaçôes vai, aos poucos, mudando seu jeito de ser: assume rapidamente o papel de "superego" de Emília, partindo de sua boca a maioria das repreensões e interditos, ignorados pela boneca. Mesmo quando participa das aventuras, geralmente é ela a porta-voz das normas, preocupações e temores da avó, Dona Benta, e nos serôes é sempre ela quem dá a palavra aos adultos, com perguntas e opiniōes pertinentes e ponderadas.

$\mathrm{O}$ arrojo e a inconsequência de criança vão desaparecendo e Narizinho se transforma num poço de virtudes, uma personagem meio 
desinteressante e secundária, em oposição a Emília que, falando e fazendo tudo o que não pode e não deve, torna-se responsável pelos momentos mais originais e hilários da obra.

Teria Narizinho crescido? Que razôes teria o escritor para conferir tal destino à trajetória da personagem?

A hipótese aqui é de que o empreendedorismo de Monteiro Lobato e seu projeto de tornar-se um editor de sucesso, em alguns momentos, tenham interferido em seu ofício de escritor, levando-o a alterar e adequar sua obra às expectativas de um mercado consumidor de bens culturais que começava a se constituir. Exemplo de menina bemeducada, de boa família, a construção da doce, carinhosa e inteligente e virtuosa Lúcia, modelo social para uma parcela importante de seus leitores - meninas dos grupos privilegiados - talvez seja uma resposta do escritor aos desejos do público consumidor.

Cabe, ainda, uma advertência: a personalidade complexa, os feitos e as ideias geniais, embora muitas vezes contraditórias e polêmicas, bem como a produção literária de Monteiro Lobato, têm sido e continuarão sendo analisadas competentemente por pesquisadores de diversas áreas, particularmente de teoria e história literária.

Este artigo pretende apenas apresentar as impressões e questionamentos de uma educadora que, como tantas pessoas de seu país, formou-se leitora pelas mãos de Monteiro Lobato e suas personagens. ${ }^{2}$

\section{Uma heroína sob encomenda}

Numa casinha branca, lá no Sítio do Picapau Amarelo, mora uma velha de mais de sessenta anos. Chama-se dona Benta. Quem passa pela estrada e a vê na varanda, de cestinha de costura e óculos de ouro na ponta do nariz, segue seu caminho pensando:

- Que tristeza viver assim tão sozinha nesse deserto...

Mas engana-se. Dona Benta é a mais feliz das vovós, porque vive em companhia das mais encantadoras das netas - Lúcia, a menina do narizinho arrebitado, ou Narizinho, como todos dizem. Narizinho tem sete anos, é morena como jambo, gosta muito de pipoca e já sabe fazer uns bolinhos de polvilho bem gostosos. (Monteiro Lobato, 1970, p. 11) 
Assim começa Reinaçôes de Narizinho, livro que reúne grande parte das histórias infantis escritas por Monteiro Lobato, de 1920 a 1931, e que inicia suas Obras Completas, organizada em 1946 para a editora Brasiliense. ${ }^{3}$

Para diversas geraçôes de crianças, estes parágrafos abriram as portas, ou melhor, as porteiras, para um mundo mágico, sem fronteiras de tempo e espaço, sem oposição entre o real e o fantástico, onde se queria e se podia "viver".

Aos poucos fomos conhecendo e nos tornando íntimos dos habitantes deste mundo, uma constelação de personagens incríveis que orbitam, neste primeiro momento, em torno de uma estrela maior: Lúcia, a menina do narizinho arrebitado.

É Narizinho quem mora com a mais carinhosa das vovós, é paparicada pela melhor cozinheira do mundo, tem o primo mais leal e corajoso, a mais engraçada das bonecas e convive com as mais interessantes criaturas. E, para completar, não há registros de que vá à escola, pelo contrário, passa os dias a subir em árvores, a brincar e a sonhar. Expressão pura dos mais (in)confessos desejos infantis.

Mas a menina faz por merecer tanta felicidade: doce, carinhosa, inteligente, bonita, dona de um forte sentimento de justiça, Narizinho é a primeira a perceber quão fluidos são os limites concretos do Sítio do Picapau Amarelo e as possibilidades que daí advêm quando entra no Reino das Águas Claras, um lugar fantástico, escondido ali, bem pertinho, dentro do ribeirão do Sítio.

Além disso, é por sua insistência, fruto da compaixão e do amor incondicional por sua boneca de pano, descrita como desajeitada de corpo e feia como uma bruxa, que o Dr. Caramujo dá à Emília uma de suas famosas pílulas, dando-lhe voz.

No entanto, a Narizinho das Reinações é, também, capaz de sentimentos e comportamentos comuns à maioria das crianças. Logo que entra no Reino das Águas Claras, por exemplo, frente à indignação do Príncipe Escamado ao ver que o guarda dos portões, o sapo Major Agarra e Não Larga Mais, dorme de roncar, a menina não só planeja uma vingança humilhante - vesti-lo com as roupas da Emília -, como incita o príncipe a chutá-lo para que acorde e ainda tortura-o, dizendo ao sapo que ele foi transformado permanentemente em velha coroca pela 
Fada do Sono (1970, p. 16). Nesta mesma visita, ainda bate boca com Dona Carochinha, que fala mal da avó, Dona Benta, e da empregada do Sítio, Tia Nastácia, e vinga-se, escondendo o Pequeno Polegar, que fugiu de sua história e está sendo procurado por ela (p. 22). Para completar, não compartilha com os adultos suas experiências, contando o segredo apenas para o primo Pedrinho (p. 52).

No episódio das Formigas Ruivas, mesmo com pena da minhoca que, sendo atacada, debate-se em sofrimento, deixa, por pura curiosidade pelo desfecho da história, que as formigas lhe tirem a vida (p. 45) e, em outro capítulo do livro, após ter sido abandonada pelo acovardado porco de estimação, o Marquês de Rabicó, no episódio do Assalto, pede a Tom Mix, o grande cowboy do cinema, que o encontre porque quer comer virado de feijão com o torresmo do Marquês (p. 58).

Em Narizinho, a consciência de pertencimento de gênero é motivo de um orgulho meio desafiador, legitimado pelo mais significativo de seus pares: na primeira visita de Pedrinho, quando questionada sobre como adivinhara qual o presente que ganharia, ela responde debochando:

- Grande coisa! Adivinhei porque conheço você. Fique sabendo, seu bobo, que as meninas são muito mais espertas que os meninos...

- Mas não tem mais muque! - replicou ele com orgulho, fazendo-a apalpar a dureza de seu bíceps, que a ginástica escolar havia desenvolvido. E concluiu: "Com este muque e com sua esperteza, Narizinho, quero ver que pode com a nossa vida!”. (Monteiro Lobato, 1970, p. 51)

Nesse livro, sua relação com Emília é marcada pela complacência e bom humor: as famosas asneiras, teimosias e pequenas crueldades da boneca são fonte de diversão e Narizinho não se furta a ironizá-la ou a mentir para ela em nome de suas brincadeiras (o casamento da boneca - Condessa de Três Estrelinhas - com o Marquês de Rabicó, por exemplo).

"Acertar o ponto" de Narizinho, porém, parece não ter sido tarefa fácil. Como mostra Bignotto (1999), as primeiras transformações sofridas pela personagem e sua trajetória antecedem em muito às que podemos identificar a partir da leitura das Obras Completas, e aparentemente inserem-se num contexto mais amplo em que Monteiro Lobato ainda tateava no ofício de escrever para crianças, buscando seu caminho. 
Segundo a autora, os textos reunidos em Reinaçôes de Narizinho foram reescritos inúmeras vezes, entre os anos de 1920 e 1930, e neste processo de aprimoramento da obra lobatiana, muitos trechos significativos acabaram sendo excluídos ou modificados.

Comparando a edição de 1920 de $A$ menina do narizinho arrebitado com a edição de 1946 de Reinaçôes de Narizinho, observam-se já no início grandes diferenças na descrição física e social das personagens.

Na primeira versão, Dona Benta, por exemplo, numa avalanche de adjetivos, é descrita como uma velha triste, de mais de setenta anos, bem no fim da vida, trêmula, catacega, sem um só dente na boca jururú -, de quem todo o mundo tem dó. Narizinho, por sua vez, tem cruamente exposta sua condição de órfã de pai e mãe, que é apenas sugerida nas versões posteriores.

Também Coelho (apud Perrotti, 1986), ao comparar a versão de 1920 com a de 1931, observa modificações importantes: na primeira versão, ao narrar a visita diária de Narizinho ao ribeirão para alimentar os peixinhos, estes são descritos por suas espécies - piquiras, guarus, lambaris, parapitingas -, com claro propósito informativo, ao passo que na segunda versão, a descrição prioriza o porte e o comportamento os miúdos chegam pertinho, os graúdos espiam de longe ressabiados , salientando o clima ficcional.

É menos relevante para este artigo, entretanto, o investimento despendido por Monteiro Lobato na lapidação de seu estilo do que seu provável esforço de adequação de sua produção literária às expectativas e demandas do público leitor, tendo em vista um mercado editorial que começava a se constituir.

Nesta perspectiva, é possível compreender outras modificações realizadas em A menina do narizinho arrebitado. Bignotto (1999) chama a atenção para a supressão de episódios contendo chacinas e um vilão assassino e aterrorizante - o Escorpião Negro -, bem como para a mudança de registro entre as duas edições no que se refere ao relacionamento entre Narizinho e o Príncipe Escamado. A curiosidade e a amizade da menina pelo peixinho, que vemos no texto de 1946, substituíram o romantismo da publicação inicial em que os dois se apresentavam como um casal de namorados: 
De protagonista a coadjuvante: o ônus das virtudes de Narizinho

- Vou confessar-te, amiga aranha, o meu grande segredo. Desde ontem que me sinto apaixonada pelo príncipe... Disse e corou.

A aranha sorriu-se e respondeu:

- E ele muito merece o amor da menina, porque não existe no mundo inteiro príncipe mais valoroso. (apud Bignotto, 1999, p. 129)

Como mostra ainda a autora, atender aos desejos do público leitor também parece ter sido a razão do "expurgo" de trechos e imagens baratinhas vestindo hábitos num hospital, por exemplo - considerados ofensivos a padres, freiras, à religião católica em geral e à "candura infantil". Em crítica de 1921 ao livro A menina do narizinho arrebitado, Altenfender Silva brada contra as calúnias e blasfêmias dirigidas ao catolicismo e acrescenta: "Não encontrará o autor outra maneira de se tornar interessante e original às crianças?" (apud Bignotto, s/d, p. 17).

$\mathrm{O}$ mesmo articulista, tempos mais tarde, em outro artigo, felicitaria o autor, que atendeu sua sugestão.

Polêmica semelhante quase impediu que a versão escolar do álbum A menina do narizinho arrebitado, publicado pela editora de Lobato, fosse adotada pela rede pública de ensino do estado do Ceará. Lourenço Filho, diretor de Instrução deste estado e articulador da adoção, para garantir a aprovação teria prometido uma edição desagravada e, em carta ao escritor, sugeriu fortemente que as partes alusivas à religião fossem suprimidas.

O fato de o escritor ter alterado sua obra a fim de ampliar a venda de livros não chega a surpreender. Como mostra Lajolo (2000), em sua biografia de Monteiro Lobato, além do talento artístico, o escritor era também dotado de um forte e arrojado espírito empreendedor, que marcaria sua atividade de empresário cultural.

Após o sucesso comercial de seu primeiro empreendimento editorial, quando Lobato publicou os resultados de uma pesquisa sobre o Saci-Pererê que havia organizado para $O$ Estado de S. Paulo, o escritor concentrou esforços em seu projeto de ganhar dinheiro com livros. Em 1918, comprou a prestigiada Revista do Brasil, que enfrentava dificuldades e a recuperou, publicando através dela obras suas e de seus amigos. Aos poucos, começou a conceber a literatura também como mercadoria e foi se tornando um editor ousado, que lançou as bases para a modernização da indústria editorial brasileira. 
Exercer a duplicidade de papéis - escritor-editor -, entretanto, aparentemente não se deu de forma fácil e vários foram os impasses, dúvidas e remorsos que atormentaram Lobato. Em carta de 30 de maio de 1921 a Godofredo Rangel (apud Lajolo, 2000, p. 34), ele expressa: "A minha obra literária, Rangel, está cada vez mais prejudicada pelo comércio. Acho que o melhor é encostar a coitadinha e enriquecer; depois de rico e, portanto, desinteressado do dinheiro, então desencosto a coitadinha e continuo. E não será longo o encostamento - uns três anos, a avaliar pela violência com que esse negócio cresce".

A concepção de livro numa óptica capitalista acompanharia Monteiro Lobato até o fim da vida, mesmo quando, após vender suas ações da Companhia Editora Nacional para cobrir as perdas sofridas pelo Crack da Bolsa de Nova York, em 1929, retomou sua atividade de escritor.

Assim como alterou e retirou trechos de sua obra, teria o escritor modificado seu projeto com relação à personagem Narizinho em função de demandas impostas pelo mercado consumidor? E, em caso de resposta positiva, quais seriam as demandas e expectativas sociais com relação à produção literária para crianças, meninos e meninas?

\section{As virtudes de Narizinho}

Naturalmente, responder a última questão implica definir quais concepções de criança estão em jogo e em que medida elas retratam contradições e fraturas ou possibilitam alianças entre grupos sociais distintos.

Da mesma forma, tratando-se de produção literária, é preciso considerar que, como afirma Zilberman (1982), o livro para crianças assumiu, desde sua origem, uma personalidade educativa, tornando-se um instrumento da escola e, muitas vezes, confundindo-se com ela e tomando-lhe o lugar. Daí a importância de se definirem também as concepções de educação e de escola envolvidas porque, mesmo que o livro reproduza a sua função, a de ensinar, pode fazê-lo numa perspectiva autoritária ou emancipadora.

Nas primeiras décadas do século XX, principalmente nos grandes centros urbanos, a formação oferecida nas escolas, aos poucos privilegiados que podiam frequentá-las, não diferia muito da formação oferecida 
nos tempos do Império, a não ser pela doutrinação cívica e patriótica, destinada a forjar o caráter nacional e coerente com o propósito republicano de formação de cidadãos.

A concepção de criança que vigorava entre os grupos médios e dominantes, derivada do modelo europeu, estava centrada na noção de desenvolvimento e parte do princípio de que a criança é um ser incompleto, impulsivo, frágil, imperfeito diante do adulto, um "vir a ser". Pode e deve, portanto, ser formada e moldada por meio da educação e da escola. A infância, por sua vez, era concebida por estes grupos como um período de inocência e felicidade, em que a sensibilidade e candura infantis deveriam ser preservadas a qualquer custo (Lajolo \& Zilberman, 1988).

Com relação à escola, através da repetição e da memorização, oferecia-se um ensino livresco e abstrato voltado para a inserção dos alunos nas mais prestigiadas escolas de ensino superior. Quer dizer, esta era a formação oferecida aos meninos porque, no que diz respeito às meninas, os objetivos educacionais eram um pouco diferentes.

Perosa (2004), em artigo que discute a constituição do espaço escolar da cidade de São Paulo, identifica, na primeira metade do século $\mathrm{XX}$, uma grande expansão do número de estabelecimentos de ensino tanto públicos quanto privados, sendo que destes últimos a maior parte era de escolas católicas. Para se ter um parâmetro, de 1900 a 1930, o ritmo de criação de escolas católicas foi de cerca de sete escolas por década, ritmo que se acelerou até 1940 com a criação de 17 escolas. Entre 1940 e 1950, estima-se que, para cada duas escolas públicas criadas, era aberta uma escola católica e, no segmento de escolas secundárias, até 1930, havia três escolas públicas contra quarenta privadas, sendo a maioria católica.

Concorreram para isso vários fatores: do ponto de vista da Igreja Católica, em uma sociedade que se tornara extremamente religiosa, a criação de escolas pode ser entendida como uma das estratégias de expansão patrimonial e administrativa que marcaram sua história naquele período. Da parte do Estado, a expansão de escolas católicas era considerada de "interesse público", já que elas supriam, de certa forma, a deficiência de estabelecimentos neste setor e prestavam serviços relevantes, sobretudo à população mais pobre da cidade. 
O fator concorrente que mais interessa aqui, entretanto, é a modificação das demandas escolares frente às transformações da estrutura econômica e social que se operava no Brasil naquele momento. Um dos efeitos do surto de industrialização e da aceleração do processo de urbanização foi o surgimento de um temor quase generalizado de que o aumento da concentração populacional - não apenas em São Paulo, mas em outros centros urbanos do país -, bem como as novas formas de convívio social que daí advinham concorreriam para a desmoralização dos costumes. Manifestado publicamente por intelectuais, compartilhado pelas famílias, o receio quanto aos perigos representados pela "sociedade moderna" teria contribuído para a ampliação da demanda por estabelecimentos privados de ensino, sobretudo confessionais, uma estratégia adotada pelos grupos médios e dominantes para proteger e garantir uma "boa educação" para seus filhos.

Se o investimento em uma boa educação para os filhos tem se constituído, há muito tempo, uma das principais estratégias de inserção, ascensão ou reprodução social para os mais diversos grupos, como nos mostram os estudos de Pierre Bourdieu e de tantos outros autores, a definição do que seria esta "boa educação" era, e de certa forma continua sendo, objetivamente influenciada pelas variáveis gênero e classe social.

Assim, se a "boa educação" dada aos meninos dos grupos privilegiados, nos grandes colégios públicos ou privados, confessionais ou não, baseava-se num programa clássico, em oposição à formação técnica ou profissionalizante oferecida em outros estabelecimentos, a "boa educação" oferecida às meninas, sobretudo pelos colégios católicos, além da formação primária e de um currículo secundário genericamente denominado "humanidades", concentrava seus esforços na formação moral.

Segundo Perosa (2004), a ênfase nesse período era a formação de mulheres aptas a ocupar seu lugar na sociedade, qual seja: o de mulheres e mães felizes - "anjos do lar" -, colaboradoras fiéis da carreira profissional de seus maridos, dedicadas à família, à educação dos filhos e à caridade. Por meio de um programa de ensino voltado, principalmente, para a produção de uma imagem de si, o cuidado com a aparência e com a apresentação, aliado à internalização de códigos comportamentais e virtudes morais constituíam as disposições físicas e psicológicas adequadas às meninas das boas famílias. 
As concepçōes de Lobato com relação à criança, escola e educação, por outro lado, são diametralmente opostas a esta visão tradicional, como bem testemunham suas obras.

Sabe-se que Monteiro Lobato foi admirador e amigo de alguns dos mais destacados representantes do escolanovismo no Brasil - Anísio Teixeira, Fernando de Azevedo e Lourenço Filho, por exemplo - e que foi um grande entusiasta desse movimento. Não é possível afirmar, entretanto, se Lobato teve contato anterior com as teorias da Escola Nova que circulavam na Europa e nos Estados Unidos desde o final do século XIX. Contudo, de acordo com Bignotto (1999), muitos anos antes destas teorias adquirirem relevância no cenário nacional, em 1920, A menina do narizinho arrebitado já inaugurava uma nova concepção de criança e um ideal de ensino que se assemelham muito às concepçóes defendidas pelo movimento da Escola Nova.

Em oposição à "escola tradicional”, a infância é vista numa perspectiva positiva, não como uma condição transitória de incompletude e imperfeição, mas como um fim em si mesmo. A criança, por sua vez, é entendida como um sujeito ativo que polariza a ação educativa. Esta, por sua vez, deve estimular a curiosidade, o pensamento, a criticidade, a imaginação, o trabalho cooperativo, de forma livre, espontânea e prazerosa, preceitos identificáveis em toda a obra infantil de Monteiro Lobato.

Colocando em confronto estes dois constructos teóricos, não é de se admirar que a obra de Lobato tenha despertado polêmica e tenha suscitado críticas, principalmente no que diz respeito à trajetória de Narizinho, já que, em que pesem os esforços do autor para democratizar seus livros e distribuí-los nas escolas públicas brasileiras, é possível supor que a maior parte se seu público consumidor fosse formada pelos segmentos mais privilegiados da sociedade, geralmente também os mais reacionários.

Em relação ao ideal de "boa educação" de meninas que vigorava na época, a personagem-menina do Sítio que subia em árvores, namorava peixes - mesmo sendo príncipes -, mentia para a avó e a deixava sozinha, enquanto viajava por lugares e épocas distantes, tinha opinião, desafiava e brigava, deve ter desagradado a muitos, uma situação bem diferente da de Emília.

No caso da boneca, seu estatuto de "gente que não é gente", ao que tudo indica, garantiu mais liberdade ao autor para conferir-lhe 
imunidade quanto aos padrōes e imposições sociais: com uma postura anárquica, original e inconsequente, Emília mente, rouba, xinga e age de forma tresloucada para conseguir o que deseja, protagonizando cenas hilárias e memoráveis aos leitores.

Já no caso de Narizinho, aparentemente a solução foi enchê-la de virtudes, de forma a não ofender os espíritos e coraçôes mais melindrosos.

Assim, logo no segundo volume das Obras Completas, "Viagem ao céu”, a menina já assume o posto de censora de Emília (que perdurará por toda a obra) e de defensora das camadas populares:

- Vou pedir a Tia Nastácia que bote as perninhas, os braços e a cabeça que faltam (no Visconde).

- Hoje? Que ideia! Exclamou a menina.

- Hoje, sim, afirmou Emília. Tia Nastácia está "lagarteando", mas negra velha não tem o direito de repousar.

Narizinho encarou-a com olhos de censura.

- Malvada! Quem neste sítio tem mais direito de descansar do que ela, que é justamente quem trabalha mais? Então negra velha não é gente? Coitada! Ela entrou no lagarto ontem. Espere mais uns dias. (Monteiro Lobato, 1949, p. 10-11)

Outra interpretação possível seria a de que Narizinho tornou-se mais virtuosa para contrabalançar a postura sempre "politicamente incorreta" de Emília, como, por exemplo, o tratamento cruel e desrespeitoso que dirige à cozinheira, uma das personagens negras e socialmente desqualificadas da obra. Em outro livro, entretanto, observa-se que seu sentimento de justiça se estende a outras situações. No livro $O$ Minotauro, ao ser convidada a entrar numa liteira, ela protesta: “- Não tenho coragem de entrar nisso, vovó! Desaforo. Gente como nós a nos carregar. Nunca! E ainda chamam a isto democracia...”. (idem, 1973, p. 127).

Narizinho também se posiciona contra as guerras. Ao saber que Péricles, em seu leito de morte, teria dito que o feito mais notável de sua vida era o fato de que nenhum ateniense nunca pusera luto por sua causa, observa: "Que beleza para o mundo se na hora da morte todos os chefes de Estado pudessem dizer o mesmo!..” (idem, ibid., p. 99).

E assim é a nossa virtuosa Narizinho, de tal forma boa, leal, sensível e justa, que seria possível elencar dezenas de passagens em que ela se 
De protagonista a coadjuvante: o ônus das virtudes de Narizinho

comove com o sofrimento alheio, fica indignada com as crueldades e defende os oprimidos, um exemplo de menina bem educada até nos padrões mais tradicionais.

Cabe então uma pergunta: teria Monteiro Lobato deixado de gostar de Narizinho? Ou os obstáculos impostos ao seu processo de criação fizeram-no deixar de lado o que seria uma fonte potencial de problemas?

É impossível responder a estas questōes, mas o fato é que, protagonista isolada da produção literária inicial do autor, a personagem-menina Narizinho foi aos poucos perdendo espaço em sua obra, até que se operou uma verdadeira cisão entre os pica-paus. Em $O$ Minotauro, que narra a viagem de toda a turma do Sítio à Grécia Antiga com o propósito de resgatar Tia Nastácia - raptada pelo monstro no livro O Picapau Amarelo -, a menina, ao invés de acompanhar Pedrinho, Emília e Visconde em suas aventuras no período micênico, permanece na Atenas de 438 a.C. juntamente com Dona Benta, na casa de Péricles. Sua estadia é preenchida por uma vasta gama de "programas de mulher": frequenta festas, trava longas conversas com Aspásia, suas amigas e a criada sobre roupas, comidas e até sobre o formato dos narizes gregos, conhece e se encanta com a arquitetura e a arte helênicas, além de fazer pipocas e batatas fritas para os atônitos gregos. Até desaparece durante toda uma tarde com o jovem e futuro general Alcebíades, mas ninguém precisa se preocupar... foi só uma brincadeira entre amigos.

No último livro escrito pelo autor, Os doze trabalhos de Hércules, os mesmos Pedrinho, Emília e Visconde, tomados pela nostalgia e pela curiosidade de assistir às aventuras do herói, retornam a Grécia Antiga. Obedecendo a determinação do primo, Narizinho fica para trás, para tomar conta de Dona Benta, que estava com reumatismo, cumprindo seu destino feminino.

\section{Notas}

1. Isso não significa, naturalmente, que a literatura fosse a única produção cultural para crianças, mas apenas que era mais legítima e valorizada. A crença na superioridade da literatura infantil e no seu poder protetor contra os malefícios da cultura de massas, aliás, perdura até hoje.

2. Entre as inúmeras polêmicas que tiveram como objeto a pessoa e a produção de Monteiro Lobato, é impossível não mencionar a mais recente, amplamente divulgada pela mídia jornalística, em que o MEC, o CNE e educadores envolveram-se num amplo debate sobre 
o caráter racista de sua obra e a pertinência de excluí-la dos currículos e bibliotecas escolares. Dada sua complexidade, não foi objetivo deste texto aprofundar essa questão.

3. Segundo cronologia elaborada por Lajolo (2000). Ver também Bignotto (1999).

\section{Referências}

BIGNOTTO, C. Personagens infantis da obra para adultos e da obra para crianças de Monteiro Lobato: convergências e divergências. 1999. Dissertação (Mestrado em Linguística) - Instituto de Estudos da Linguagem da Universidade Estadual de Campinas, Campinas.

BIGNOTTO, C. Monteiro Lobato em construção. s/d. Disponível em: <http://www.unicamp.br/iel/monteirolobato/outros/cilza01Lobato.pdf>. Acesso em: 5 jun. 2009.

LAJOLO, M.; ZILBERMAN, R. Literatura infantil brasileira, história e histórias. 4. ed. São Paulo: Ática, 1988.

LAJOLO, M. Usos e abusos da literatura na escola: Bilac e a literatura escolar na República Velha. Rio de Janeiro: Globo, 1982.

LAJOLO, M. Monteiro Lobato: um brasileiro sob medida. São Paulo: Moderna, 2000.

MONTEIRO LOBATO, J.B. Reinações de Narizinho. 23. ed. São Paulo: Brasiliense, 1970.

MONTEIRO LOBATO, J.B. Viagem ao céu. 9. ed. São Paulo: Brasiliense, 1949.

MONTEIRO LOBATO, J.B. Os doze trabalhos de Hércules - Tomo I. 4. ed. São Paulo: Brasiliense, 1965.

MONTEIRO LOBATO, J.B. D. Quixote das crianças/O Minotauro. vol. 2b. São Paulo: Brasiliense, 1973.

PEROSA, G.S. Grupos familiares, investimentos educacionais e o mercado escolar de São Paulo em 1930. Pro-Posiçôes, Campinas, v. 15, n. 2 (44), p. 61- 76, maio/ago. 2004.

PERROTTI, E. O texto sedutor na literatura infantil. São Paulo: Ícone, 1986. 
De protagonista a coadjuvante: o ônus das virtudes de Narizinho

ZILBERMAN, R. Literatura infantil: Livro, leitura, leitor. In: ZILBERMAN, R. (Org.). A produção cultural para a criança. Porto Alegre: Mercado Aberto, 1982.

ZILBERMAN, R.; MAGALHĀES, L.C. Literatura infantil: autoritarismo e emancipação. São Paulo: Ática, 1984.

Recebido em 10 de junho de 2009.

Aprovado em 20 de novembro de 2011. 